\title{
PROJETO DE INTERFACES DE COMPONENTES ESTRUTURAIS PARA SISTEMAS CONSTRUTIVOS PRÉ-FABRICADOS COM EMPREGO DE MADEIRA DE FLORESTAS PLANTADAS
}

\section{INTERFACE DESIGN OF STRUCTURAL COMPONENTS FOR CONSTRUCTION SYSTEMS PRE- MANUFACTURED WITH THE USE OF WOOD FROM PLANTED FORESTS}

\author{
João Marcelo Danza Gandini, M.Sc. (PUC-MG); \\ Tomaz Queiroz Ferreira Barata, Dr. (UNESP); \\ Javier Mazariegos Pablos, Dr. (USP)
}

\author{
Palavras Chave \\ Madeira Certificada; Pré-fabricação; Componentes Estruturais; Sistemas Construtivos
}

\section{Key Words}

Certified Wood; Pre-manufactured; Structural Components; Constructive System

\section{RESUMO}

Considerando uma crescente preocupação quanto à possibilidade de limitação de recursos naturais disponíveis para a produção de bens materiais, os efeitos das mudanças climáticas decorrentes da degradação do meio ambiente e a importância do emprego de materiais locais de fontes renováveis na produção de produtos "mais" sustentáveis, o trabalho visa contribuir para a utilização de madeira de florestas plantadas na arquitetura e construção civil. O objetivo é demonstrar o caráter sustentável da madeira de florestas plantadas como material construtivo para utilização em interfaces de componentes estruturais pré-fabricados. A metodologia visou a apresentação do caráter sustentável da madeira de florestas plantadas; levantamento acerca da madeira de florestas plantadas no Brasil, definição de sistemas construtivos com componentes pré-fabricados em madeira e; propostas de interfaces entre componentes estruturais. Como resultados foi demonstrada a viabilidade de utilização da madeira de florestas plantadas para a construção civil, levando em consideração, principalmente sua viabilidade técnica e os aspectos sustentáveis de sua utilização.

\section{ABSTRACT}

Whereas a growing concern about the possibility of limitation of available natural resources for the production of material goods, the effects of climate change resulting from degradation of the environmental and the importance of the use of local materials from renewable sources in the production of products "more" sustainable, the study aims to contribute to the use of wood from planted forests in architecture and construction. Objective: To demonstrate the sustainable character of wood from planted forests as a building material for use in interfaces of structural components pre-manufactured. The methodology aimed to presentation of the sustainability of the use of wood from planted forests; survey about the wood from planted forests in Brazil; definition of construction systems with components pre-manufactured in wood and; proposals for interfaces between structural components. As results was demonstrated the viability of using wood from planted forests for civil construction taking into consideration especially its technical feasibility and sustainable aspects of their use. 


\section{INTRODUÇÃO}

Hoje, as alterações climáticas iniciadas no século XX tornam-se cada vez mais evidentes e representam um dos maiores desafios ambientais do século XXI, sendo que a degradação do meio ambiente está diretamente ligada às atividades humanas, como o aumento de emissão de gases do efeito estufa (GEE) gerado pela queima de combustíveis fósseis.

A sustentabilidade, segundo Boff (2012), é umas das palavras mais utilizadas na atualidade, tanto por empresas, profissionais e meios de comunicação, sendo uma etiqueta aplicada a produtos e processos no intuito de agregar-lhes valor e muitas vezes reduzindo-a uma estratégia de negócio. Este conceito tem sido um tema altamente discutido a nível mundial juntamente com o aquecimento global, abrangendo diversos campos como a construção civil, arquitetura, design, indústrias, dentre outros. Contudo, as agressões à natureza e ao meio ambiente, bem como a utilização de produtos tóxicos em alguma etapa do ciclo de vida de produtos e/ou destinação de resíduos, algumas vezes não degradáveis, são comumente omitidas pela utilização do substantivo sustentabilidade. Isto reflete a dinâmica global, algumas vezes contrariada por atitudes localizadas, realmente sustentáveis, na gestão de energia, uso dos recursos hídricos, atividades de reflorestamento e utilização de produtos e processos realmente sustentáveis.

A madeira tem-se revelado um material muito promissor no Brasil, contudo a utilização de espécies nativas requer, além da certificação das áreas de manejo, um estudo mais aprofundado no que diz respeito ao consumo energético entre o corte e o produto final, devido ao fato das reservas se concentrarem principalmente na floresta amazônica, o que aumenta significativamente o gasto energético no transporte do material, realizado por via rodoviária até os centros de consumo, fazendo sentido sua utilização somente em locais próximos à região Norte do país. Dentro deste raciocínio, a utilização de madeiras provenientes de áreas reflorestadas se torna uma alternativa mais sustentável, uma vez que seu ciclo de renovação é mais curto que o das madeiras nativas e as distâncias dos locais de plantio aos centros consumidores são menores.

Além disso, o aproveitamento integral da matéria-prima madeira através de processos industriais aparece como importante fator na sua transformação em lâminas e painéis, onde a utilização de colas e vernizes adequados e de baixa toxidade pode dar origem a complexas estruturas, painéis de fechamento, componentes construtivos e elementos de coberturas. Tal fato é de extrema importância na cadeia sustentável, pois a madeira industrializada não encerra seu ciclo na desmontagem da obra, podendo ser considerada matéria-prima para reutilização, evitando-se assim desperdícios e geração de resíduos durante o processo. A industrialização supre também o lado social do tripé sustentável (meio ambiente, promoção social, promoção econômica), pois não requer uma mão-de-obra totalmente especializada, treinada e qualificada para as operações, gerando oportunidades de crescimento profissional.

Segundo Agopyan e John (2011), o tripé sustentável deve ser considerado de maneira integrada, pois ao contrário, não será possível o alcance do desenvolvimento sustentável, pois "o desafio é fazer a economia evoluir, atendendo às expectativas da sociedade e mantendo o ambiente sadio para esta e para futuras gerações".ᄀ

\section{MATERIAIS E MÉTODOS}

A metodologia adotada no trabalho priorizou a realização de pesquisa bibliográfica e o levantamento de dados sobre a situação florestal e a capacidade de produção de madeira proveniente de atividades de silvicultura no país e a tipologia de interfaces entre componentes construtivos. Para tanto, foram abordados neste estudo os seguintes aspectos: a) $\mathrm{O}$ caráter sustentável da utilização de madeira proveniente de florestas plantadas, suas características e especificidades para a aplicação em construções racionalizadas. Neste item são apresentados dados sobre a quantidade de energia necessária para a produção de diversos materiais e aspectos gerais sobre a cadeia produtiva de base florestal no país; b) Levantamento de madeira de florestas plantadas no Brasil, abordando aspectos sobre as áreas de plantios florestais de Pinus e Eucalyptus, a localização dos principais polos consumidores, entre outros gráficos comparativos tendo com fonte a Associação Brasileira de Produtores de Florestas Plantadas (ABRAF); c) Definição e apresentação de sistemas construtivos com componentes pré-fabricados em madeira e; d) Apresentação e descrição das principais características de interfaces entre os principais componentes estruturais de madeiras.

\section{RESULTADOS E DISCUSSÕES}

São apresentados nesta seção os aspectos pertinentes à sustentabilidade no uso da madeira, uma análise do potencial da madeira proveniente de florestas plantadas por meio de dados governamentais, e uma análise da disponibilidade de madeira através da apresentação de gráficos e dados estatísticos entre produção e consumo para diversos fins. 


\subsection{A madeira como material sustentável}

O desenvolvimento sustentado pode ser alcançado pelo setor florestal não só pela produção direta de madeira e de matéria-prima na fabricação de produtos dela derivados, mas pela geração de outros bens, sempre primando pela manutenção do equilíbrio ecológico. Segundo OLIVEIRA (1997), a atividade florestal com o emprego de métodos racionais de exploração, poderá conjugar a expansão econômica à conservação da qualidade de vida.

Segundo PFEIL (2003), a madeira é provavelmente o material de construção mais antigo por sua disponibilidade na natureza e sua relativa facilidade de manuseio, sendo que, quando comparada a outros materiais de construção utilizados na atualidade, ela apresenta uma excelente relação resistência/peso. Outras características favoráveis ao uso da madeira em construção são a facilidade na fabricação de diversos produtos industrializados e satisfatório isolamento térmico.

Ainda segundo o autor, a madeira é um material de construção empregado pelo homem desde épocas pré-históricas. Mesmo até o século XIX, algumas das mais importantes obras de engenharia foram construídas em pedra ou madeira, combinando-se frequentemente os dois materiais. Apesar do longo período de utilização, só na primeira metade do século XX é que foram estabelecidas teorias, processo de cálculo estrutural e técnicas construtivas aplicadas a estruturas de madeira. Atualmente a utilização da madeira como material de construção economicamente competitivo e aceitável em termos ecológicos se baseia nas técnicas mais modernas de reflorestamento conciliadas ao desenvolvimento de produtos industrializados de madeira com elevada qualidade.

Os produtos de base florestal podem contribuir não apenas para a manutenção ou aumento de estoque de carbono nas áreas de plantio, mas também para evitar as potenciais emissões associadas ao uso de produtos oriundos de matérias-primas fósseis ou não renováveis em diferentes etapas da cadeia produtiva, o que traz inúmeros benefícios às atuais condições climáticas.

Segundo o Centro Nacional para o Desenvolvimento da Madeira da França (CNDB) apud GAUZIN-MULLER (2001), 1,0 tonelada de madeira utilizada na construção representa cerca de 1,6 toneladas de $\mathrm{CO} 2$ a menos na atmosfera, pois ao ser utilizada a madeira retém seu estoque de $\mathrm{CO} 2$ absorvido durante sua vida, ao contrário de sua queima ou decomposição natural, que promovem o retorno do gás carbônico para a natureza.

Pode-se destacar, portanto, que existem dois tipos de potenciais benefícios climáticos diretamente associados à produção de florestas: os estoques de carbono nas áreas de plantio e as potenciais emissões evitadas por meio do uso de produtos florestais bem manejados ao invés de produtos de base fóssil ou não renovável em diferentes etapas da cadeia produtiva.

Outro fator a ser considerado para utilização de materiais de base florestal está pautado na quantidade de energia necessária para a produção de materiais atualmente destinados à construção civil, como o aço, o concreto e o alumínio, conforme apresentado na Tabela 1.

Tabela 01: Energia necessária em kWh para a produção de $1 \mathrm{~m}^{3}$ de componentes construtivos

\begin{tabular}{|l|c|}
\hline \multicolumn{1}{|c|}{ Material } & Consumo energético (kWh) \\
\hline Madeira & 8 a 30 \\
\hline Concreto & 150 a 200 \\
\hline Peças de construção em aço & 500 a 600 \\
\hline $\begin{array}{l}\text { Peças de construção em } \\
\text { alumínio }\end{array}$ & 800 \\
\hline
\end{tabular}

Fonte: CRUZEIRO (1998)

Pode-se compreender porque a madeira é amplamente utilizada em países desenvolvidos, mesmo sendo eles detentores das técnicas mais avançadas no uso de materiais como o aço, pois o custo energético da produção de componentes de madeira é praticamente nulo, quando comparado aos outros materiais citados.

A utilização de materiais como o concreto, o aço e o alumínio não pode e não deve ser descartada, pois mesmo à custa de um maior consumo de energia tais materiais são imprescindíveis em certas ocasiões. O que se deve levar em consideração é a utilização destes materiais de maneira mais coerente e condizente com a realidade em que vivemos, enfatizando os fatores ambientais e a sustentabilidade.

Em relação ao Brasil, um dos fatores que contribuíram para a não utilização da madeira como material construtivo foi sua própria colonização, que por herança dos portugueses passou a construir com pedra e/ou terra (adobe e taipa), resultando em uma interpretação equivocada dos materiais e da linguagem decorrente de seu uso. $\mathrm{O}$ modelo dominante atual e quase hegemônico das construções brasileiras é a utilização do concreto armado e alvenaria de tijolos cerâmicos e/ou de concreto.

Países da Europa e os Estados Unidos modernizaram seu parque industrial após a 2a Guerra Mundial, principalmente no que diz respeito a sistemas pré-fabricados em madeira devido a fatores como demanda habitacional e necessidade de racionalização de processos construtivos, 
ao contrário do Brasil que devido mais a questões culturais e políticas do que tecnológicas, não se utiliza de tais sistemas, limitando-se ao uso da madeira em subsistemas de cobertura na construção civil, sendo este setor o que menos consome madeira proveniente das florestas plantadas (VALLE, et al., 2012).

A cadeia produtiva do setor brasileiro de base florestal associado às florestas plantadas desempenham importantes funções sociais, econômicas e ambientais. Do ponto de vista social compreendem a produção, a colheita e o transporte de madeira. No que diz respeito às funções econômicas, destaca-se a obtenção dos produtos finais nos segmentos industriais de papel e celulose, painéis de madeira industrializada, madeira processada mecanicamente, siderurgia a carvão vegetal e biomassa, entre outros. As funções ambientais de maior importância são a conservação dos recursos hídricos, a conservação da biodiversidade e a estabilidade climática.

A noção de construção sustentável deve estar presente em todo o ciclo de vida dos empreendimentos. As edificações devem ser concebidas e planejadas para que suprimam menores áreas de vegetação, otimizem o uso de materiais, demandem menos energia e água durante sua fase de construção, operação e desmontagem. Tais atitudes contribuem para a minimização da geração de resíduos; tornam as edificações mais duráveis, flexíveis e passíveis de requalificação; proporcionam menores custos de manutenção; geram opções para desmontagem ao invés da demolição, bem como o reaproveitamento e reciclagem dos materiais utilizados no fim de seu ciclo de vida.

\subsection{Levantamento da madeira de florestas plantadas no Brasil}

O Brasil, em 2010, encontrava-se na oitava posição mundial de superfície de florestas plantadas (SFB, 2013). Em 2012, a área brasileira de plantios de Eucalyptus e Pinus atingiu 6,66 milhões de hectares, que representaram $76,6 \%$ e $23,4 \%$ respectivamente (ABRAF, 2013), sendo que a madeira plantada é proveniente de florestas localizadas majoritariamente nas regiões sul e sudeste do país. Consideradas como monocultivo, sua produtividade é de aproximadamente $40 \mathrm{~m}^{3} /$ ha.ano, maior que em países como a Finlândia, Suécia e Chile, tradicionalmente madeireiros (ABRAF, 2015).

Os estados com as maiores superfícies de plantio são Minas Gerais, São Paulo, Paraná e Santa Catarina, conforme apresentado na Figura 1, justamente por ser nestes estados que se concentram a maioria das unidades industriais e centros consumidores.
Figura 01 - Distribuição de áreas de plantios florestais com Pinus e Eucalyptus no Brasil em 2012

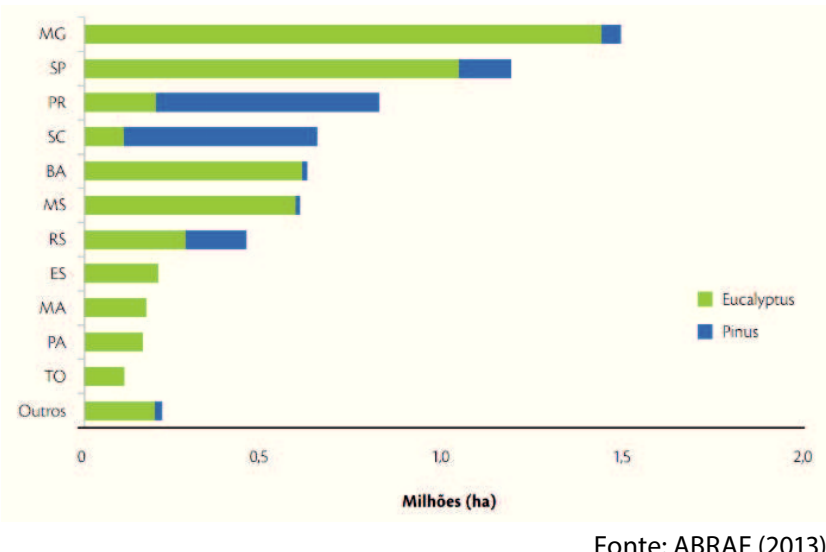

A grande produtividade da silvicultura brasileira se dá devido a um conjunto de situações, tais como as condições climáticas e fundiárias, investimentos em pesquisas e desenvolvimento para melhora genética, otimização de áreas de manejo e a qualidade da mão de obra empregada. Estes fatores proporcionam um menor ciclo de colheita, o que confere ao Brasil, uma posição de destaque no cenário mundial, verificada na Figura 2 (ABRAF, 2013).

Figura 02 - Comparação da produtividade florestal de coníferas e de folhosas no Brasil com países selecionados, 2012

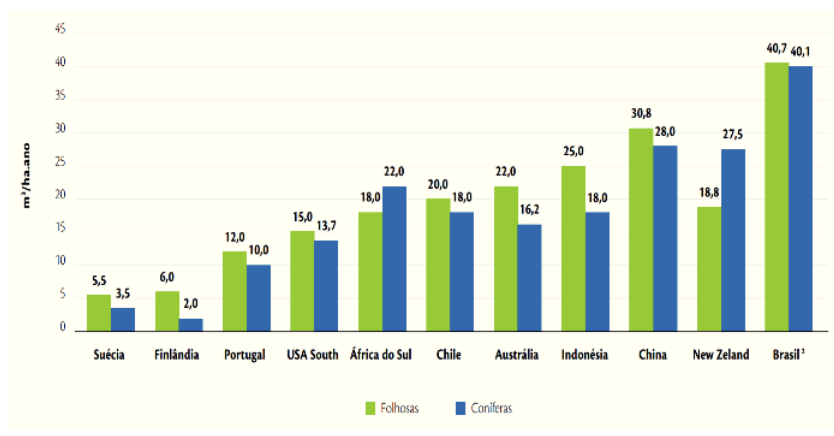

Fonte: ABRAF (2013)

As dimensões continentais do Brasil favoreceram o desenvolvimento do parque industrial de base florestal ao longo de todo o seu território, contribuindo para a diversificação da cadeia produtiva de madeira plantada, destacando-se a produção de chapas de madeira industrializada, madeira processada mecanicamente, madeira tratada, celulose e papel, carvão vegetal para siderurgia e biomassa para energia. Contudo, as indústrias e empresas se concentram principalmente nas regiões sul e sudeste, devido a aspectos regionais e logísticos que contribuem para o aumento dos níveis de competitividade. A Figura 3 apresenta a localização das principais empresas e polos consumidores de madeira de florestas plantadas no Brasil no ano de 2012. 
Figura 03 - Localização das principais empresas e pólos consumidores de madeira de florestas plantadas no Brasil

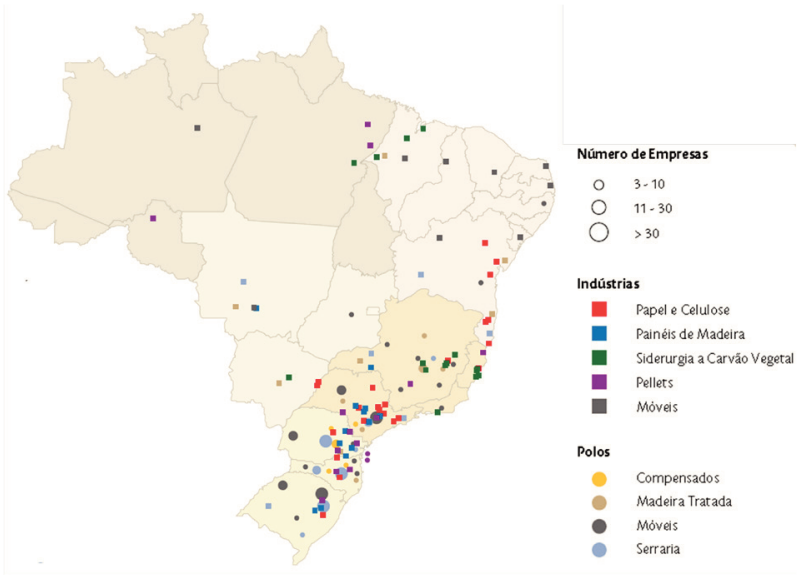

Fonte: ABRAF (2013)

\subsection{Sistemas construtivos com componentes} pré-fabricados em madeira

Sistema construtivo em madeira pode ser definido, segundo Cunha e César (2004), como sendo a organização de componentes, elementos e subsistemas feitos em madeira e dispostos de modo a constituir uma edificação para abrigar atividades humanas. Os autores ressaltam que no processo de classificação dos sistemas, existem diversos critérios para agrupar as soluções construtivas, podendo ser os sistemas arranjados segundo o grau de industrialização da construção.

Sobre a experiência de construção em madeira nos Países Andinos, a Junta Del Acuerdo de Cartagena (JUNAC, 1984) agrupa os sistemas construtivos em não industrializados (sistema vernacular e pré-cortado) e industrializados (sistema pré-cortado, pré-fabricação parcial, em painéis e componentes e pré-fabricação total ou volumétrica) devido à quantidade de trabalho realizado na fábrica ou na obra, desde a transformação da madeira a peças de seções e tamanhos distintos até a fabricação completa de elementos volumétricos, tendo como características:

- Sistema vernacular: utiliza sistemas e materiais de construção tradicionais, sendo executado completamente no local da obra, com aplicação de pouca tecnologia moderna;

- Sistema semi pré-cortado ou habilitado: as peças de madeira chegam ao canteiro de obra cortadas somente com as seções finais. Os cortes nos comprimentos, rebaixos nas peças e perfurações são realizados na obra;

- Sistema pré-cortado: considerado o método mais antigo de pré-fabricação e um dos mais populares. As peças chegam ao canteiro nas dimensões de uso final, tanto nas seções quanto nos comprimentos, incluindo também os rebaixos e recortes necessários. É um sistema apropriado para a construção de edificações em série, devido à facilidade de produção de peças com mesma seção e comprimento;

- Sistema de pré-fabricação parcial, subdivido em: a) sistema de pré-fabricação de painéis, geralmente construídos com critérios de coordenação modular; b) sistema de pré-fabricação de componentes, que consiste na fabricação de componentes que incluem instalações e acabamentos primários.

- Sistema de pré-fabricação total ou volumétrica: sistema de montagem tridimensional onde as edificaçôes são montadas na fábrica, sendo transportadas para a obra onde são realizadas poucas etapas, tendo como principal a execução de fundações.

Os sistemas industrializados, classificados por Bittencourt (1995) como sistema construtivo racionalizado, visto que as atividades em canteiro de obra são exclusivamente de encaixe e montagem dos componentes, têm como principais vantagens: a otimização econômica e ecológica das edificações; a redução no desperdício de materiais e melhor gestão de resíduos; a redução de mãode-obra qualificada devido ao aumento da produção mecanizada; a redução no prazo de execução de obra e ociosidade de mão de obra, minimização de erros construtivos e poluição nos canteiros; o aumento da qualidade dos componentes e consequentemente da edificação; a redução dos custos de produção devida à padronização de peças e componentes produzidos em série.

\subsection{Propostas de interfaces entre componen- tes estruturais}

Neste item serão apresentadas interfaces entre os componentes estruturais pilar-fundação, pilar-viga e viga-viga. As propostas apresentam algumas alternativas passiveis de utilização no tipo de sistema construtivo pilar-viga.

Destaca-se a baixa complexidade de montagem das interfaces, possibilitando a execução por profissionais que não possuem uma grande qualificação para trabaIhar com a madeira, pois as peças já saem das unidades de pré-fabricação com a furação para posicionamento dos conectores metálicos principais, sendo necessário somente a execução de furação secundária em obra.

\subsubsection{Interface pilar-fundação}

A interface entre os componentes pilar-fundação é realizada com o auxílio de conectores metálicos fixados nos pilaretes de concreto e parafusados no pilar de madeira, conforme apresentado na Figura 4. 
Figura 04 - Interface pilar-fundação

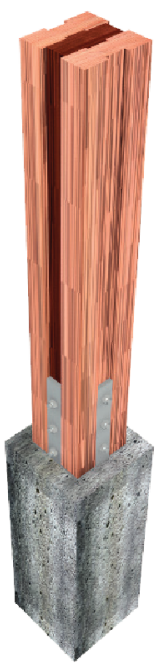

Figura 06 - Interface pilar-2 vigas com mão francesa
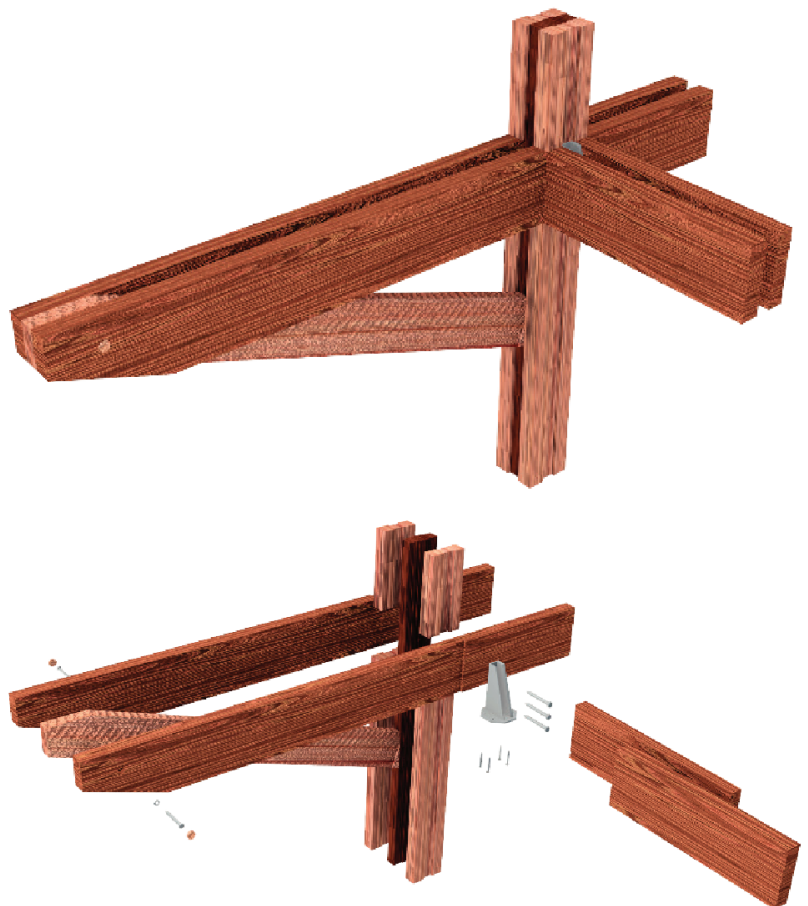

Fonte: Elaborada pelos autores

\subsubsection{Interface pilar-2 vigas duplas de canto}

Uma outra variação de interface entre pilar-viga, apresentada na Figura 7, é o posicionamento das vigas em uma situação de canto, onde são utilizados parafusos de rosca soberba, afim de que tais peças metálicas não fiquem expostas na face externa do pilar e consequentemente ação de intempéries.

Figura 07 - Interface pilar-2 vigas duplas de canto
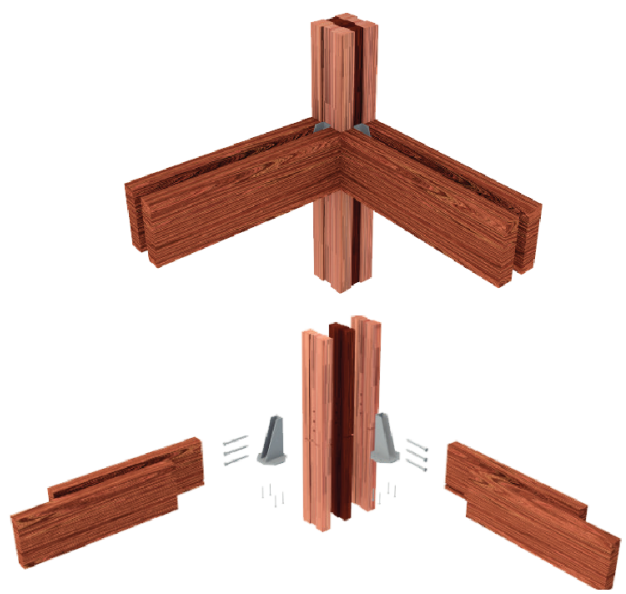

Fonte: Elaborada pelos autores

\subsubsection{Interface viga-viga}

Neste item é apresentada uma proposta para interface entre uma viga dupla com outras 2 vigas duplas perpendiculares à primeira, com utilização de conector metálico e barra roscada, conforme pode ser visto na Figura 8. 
Figura 08 - Interface viga-viga

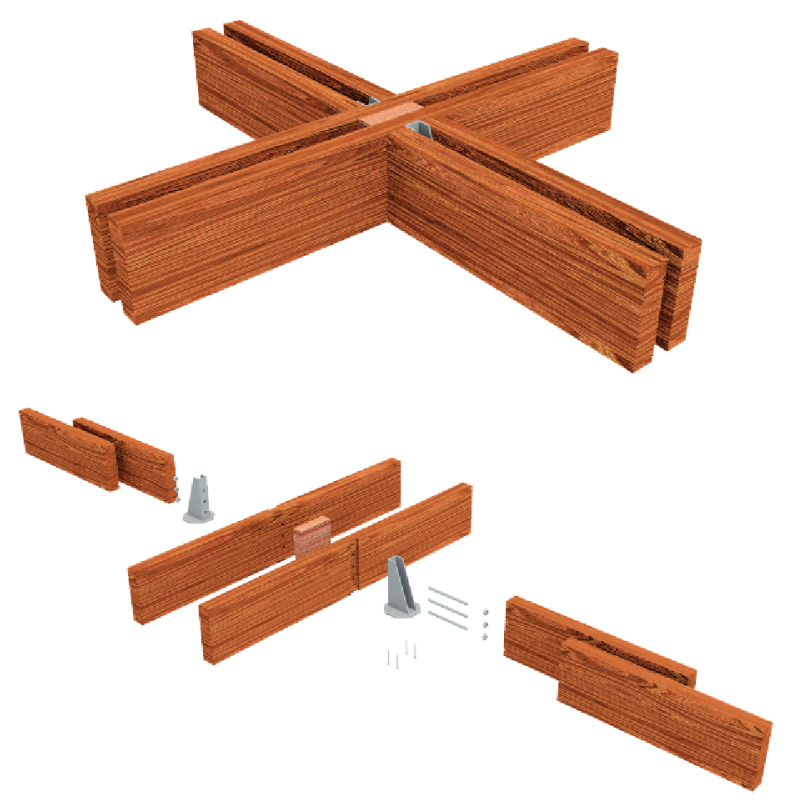

Fonte: Elaborada pelos autores

\section{CONCLUSÕES}

As atuais tendências globais de uso racional de recursos renováveis assim como os processos de certificação e as restrições ambientais ao uso de madeiras nativas reforçam a necessidade de uma maior utilização de madeiras de florestas plantadas, sobretudo do gênero Eucalyptus, que vem apresentando crescimento de área de plantio.

A construção civil é um segmento que tem muito a contribuir com o caráter sustentável na obtenção, gestão e utilização dos materiais, principalmente na busca de alternativas para o desperdício praticado nos canteiros de obras dos sistemas tradicionais de construção, que têm como características principais a lentidão no processo construtivo, desperdício de materiais e consequentemente a geração de resíduos. O combate ao desperdício se dá ainda durante o processo produtivo, pela adoção de tecnologias menos intensivas em energia e que requeiram menos matérias-primas.

Uma análise da cadeia produtiva da madeira como matéria-prima na construção de edificações com a utilização de sistemas industrializados é necessária para a otimização do uso de materiais que podem contribuir de forma substancial para o desenvolvimento sustentável, com ênfase na redução da emissão de carbono na atmosfera, redução e reaproveitamento de resíduos gerados nas unidades de pré-fabricação e nos locais da obra, geralmente descartados sem nenhum tipo de controle ambiental.

\section{REFERÊNCIAS}

ABRAF - Associação Brasileira de Produtores de Florestas Plantadas. Anuário Estatístico ABRAF 2013 - ano base 2012, Brasília: (2013). Disponível em <www.abraflor.org.br/estatisticas.asp >. Acesso em 30 ago. 2015>. Acesso em: 14 abr. 2015.

AGOPYAN, V., JOHN, V. M. O desafio da sustentabilidade na construção civil. Série Sustentabilidade, v.5. José Goldemberg (Coord.). São Paulo: Blucher, 2011. ISBN 978-85-212-0610-1

BARATA, T.Q. F., GANDINI, J.M. D., Projeto Arquitetônico e Estrutural em Madeira para Unidade Habitacional, In: CIMAD 11 - $1^{\circ}$ Congresso Ibero-LatinoAmericano da Madeira na Construção, 2011, Coimbra, Portugal.

BARATA, T. Q. F., GANDINI, J. M. D., Projeto de Produção de Componentes e Processo de Montagem de Sistemas Construtivos Pré-Fabricados com Emprego de Madeira Certificada, In: XII Encontro Brasileiro em Madeira e em Estruturas de Madeira, 2012, Vitória - ES. Anais... Vitória, 2012.

BARATA, T. Q. F.; GANDINI, J. M. D. Sistema Construtivo em Madeira Certificada para a Ampliação da Sede do IMAFLORA - Piracicaba, SP, In: Encontro Brasileiro Em Madeira e em Estruturas De Madeira, 10.,2008, Londrina. Anais...Londrina, 2008.

BITTENCOURT, R.M. Concepção arquitetônica da habitação em madeira, 1995. 247p. Tese (Doutorado) - Escola Politécnica da Universidade de São Paulo, São Paulo, 1995.

BOFF, L., Sustentabilidade: o que é - o que não é, Petrópolis, RJ, Editora Vozes, 2012.

CAMPOS, E.F., PUNHAGUI, K. R. G., JOHN, V. M. Emissão de $\mathrm{CO} 2$ do transporte da madeira nativa da Amazônia. Revista Ambiente Construído, Porto Alegre, v. 11, n. 2, p. 157-172, abr./jun. 2011.

CORBELLA, O.; YANNAS, S. Em busca de uma arquitetura sustentável para os trópicos: conforto ambiental, 1.ed. Rio de Janeiro: Revan, 2003.

CRUZEIRO, E. C., Produção e construção de casas em madeira de reflorestamento sistema I.F. São Carlos, 1998. 283 p. Dissertação (mestrado) - Escola de Engenharia de São Carlos - Universidade de São Paulo (EESC/USP). 
DEL CARPIO, J. C. Ensambles em madera, redescrubrimiento del ensamble tradicional - uma orientación em la construcción em américa latina, 110 p. - Centro latinoamericano de promocionn y desarrollo de la madera, CAMBIUM - Lima, 1990.

GANDINI, J.M.D., Aplicação de conceitos de sustentabilidade no desenvolvimento de projeto de componentes estruturais pré-fabricados com emprego de madeira de florestas plantadas. Dissertação (Mestrado) - Instituto de Arquitetura e Urbanismo de São Carlos - Universidade de São Paulo, 2016.

GANDINI, J. M. D.; BARATA, T. Q. F.; PABLOS, J. M. O caráter sustentável da utilização de madeira de florestas plantadas para a arquitetura e construção civil. In: Encontro Brasileiro Em Madeira e em Estruturas De Madeira, 15.,2016, Curitiba. Anais... Curitiba, 2016.

GAUZIN-MULLER, D., Arquitetura Ecológica, 304 p. São Paulo. Editora Senac São Paulo, 2011.

JUNTA DEL ACUERDO DE CARTAGENA PADT-REFORT. Manual de diseño para maderas del grupo andino, 1 ed. Lima: JUNAC, 1984.

OLIVEIRA, J. T. S. Características da madeira de eucalipto para a construção civil, São Paulo, 1997. 429p. Tese (Doutorado). Escola Politécnica, Universidade de São Paulo.

PFEIL, W., PFEIL, M. Estruturas de Madeira, Rio de Janeiro, 6 ed., Livros Técnicos e Científicos, 2003.

PUNHAGUI, K. R. G. Potencial de reducción de las emisiones de $\mathrm{CO} 2$ y de la energia incorporada en la construcción de viviendas en Brasil mediante el incremento del uso de la madera. 2014. Tese (Doutorado) - Universidad Politécnica de Cataluña y Universidade de São Paulo. Barcelona, 2014.

SFB - Serviço Florestal Brasileiro. Florestas do Brasil em resumo - 2010: dados de 2005-2010. Serviço Florestal Brasileiro. - Brasília: SFB, 2010. 152 p.

SFB - Serviço Florestal Brasileiro. Florestas do Brasil em resumo - 2013: dados de 2007-2012. Serviço Florestal Brasileiro. - Brasília: SFB, 2013. 188 p. - disponível em <http://www. florestal.gov.br/publicacoes/tecnico-cientifico/florestas-do-brasil-em-resumo-2013>. Acesso em: 15 jul. 2013.
VALLE, I. M. R.; INO, A; FOLZ R. R.; CALLIL J. - A PréFabricação na Construção em Madeira no Brasil. In: XII Encontro Brasileiro em Madeira e em Estruturas de Madeira, 2012, Vitória - ES. Anais... Vitória, 2012. 